\title{
THOMAS LUCAS AND HIS EMBOSSED STENOGRAPHIC CHARACTERS*
}

\author{
BY \\ P. V. MILLS $\dagger$ \\ Bristol Eye Hospital and Department of Ophthalmology, University of Bristol
}

LITTLE is known of the life and work of Mr. Thomas Mark Lucas, who was born two hundred years ago. His important contribution to the development of embossed characters which enable the blind to read deserves wider recognition.

He was born in Bristol in 1764, but there are no records existing to tell us anything of his early life or of his family. However, his father was evidently concerned for the religious welfare of his son, and Thomas Lucas later recalled the effect that his first acquaintance with the Bible had evoked: "In the year $1777 \mathrm{my}$ late dear father purchased for me a neat pocket Bible. In this blessed book I learnt to know myself and to feel that I was a sinner .... This blessed book has proved to me a never failing source of consolation." He remained a man of deep religious conviction throughout his life.

In the early part of the nineteenth century he resided in Castle Street, Bristol, and was occupied as both a merchant and a teacher of shorthand. It was during this period that he began to interest himself in the problem of teaching the blind to read. He was aware that books with embossed characters had been developed for this purpose since 1771. Most of these books used the Roman alphabet or some modification thereof, and were excessively large and costly. The idea that enabled Lucas to overcome these difficulties was evidently stimulated by a conversation which he recounts as follows:

In the year 1831, Mr. George Pocock, of this city, received the following remarks on teaching the blind to read with simple characters, from Lady Charlotte Erskine.

"In choosing characters for teaching the blind to read, it seems to be an error to pay much attention to similarity with those of any known alphabet; simplicity and perspicuity ought to be the objects chiefly kept in view; remembering that the generality of those for whose use the proposed alphabet is intended are ignorant of any character, and must therefore, like children, begin to learn their a b c. And even were this not the case, the difficulty of learning a totally new character is soon conquered; as all scholars in German, Greek and Hebrew, have experienced; for these reasons the

* Received for publication November 25, 1964.

† Present address: Bath Eye Infirmary, Lansdown Road, Bath. 
simplicity of an alphabet for the blind ought not to be sacrificed to the desire of assimilating it to that in common use ... the characters ought to be as simple as possible; ... they ought to be clear and distinct, but not very large, because the larger the surface is, the more time is required to ascertain the form by the fingers, etc., therefore the process of reading is impeded. And it is evident that the large size of the characters must add to the bulk and expense of the book."

Ever since the receipt of the above, I have been employing my thoughts on the most simple plan for teaching the blind [to read]...

Lady Charlotte Erskine herself had for several years been active in teaching blind persons to read. As a result of "employing his thoughts" Lucas had the brilliant idea that if the embossed characters were made similar to the symbols used in stenography, the blind person should be able to read words as fast as they are spoken. By 1832 he had developed such a system, and in 1837 he published a small book entitled Instructions for Teaching the Blind to Read, which has the following introduction:

To the Friends of the Blind.

It is with heartfelt pleasure that I embrace this opportunity of announcing, in the seventy-third year of my age, that, through the kind providence of God, the blind are now taught to read in as short a space of time, and as fluently, as those who can see: and that their books are reduced more than one half, both in size and price.

This has been effected, first, by employing the most simple characters that can be invented for letters; and, secondly, by using no more letters in spelling words than will sound them; and thirdly, by making every letter to represent some syllable or word.

This method, similar to that adopted in short-hand writing, appears absolutely necessary; because, as the short-hand writer must form the letters and words as fast as the public speaker utters them, so the finger-reader must pass the fingers over the letters and distinguish them as fast as the tongue proclaims them. By this simple plan finger-reading is rendered a most pleasing exercise, so that all who are deprived of sight may be blessed with a liberal education. To God alone be the glory.

T. M. Lucas.

He further claimed that with his system a blind child could be taught to read in "not more than half the time that would be requisite in the manner we are taught who are blest with sight, for the blind need few letters, only about half the number we use for any book".

The characters used consisted of straight lines of two different lengths and semicircles of two different radii, set at varying angles and combined with dots to give an appearance rather like a crotchet in conventional music notation (Fig. 1). The alphabet thus derived Lucas designated the Britannic or Universal Alphabet.

In order to bring his new method to the attention of the public he frequently gave lectures during which his blind pupils would demonstrate their reading ability to an astonished audience. Numerous testimonials reprinted at the end of the second edition of his Instructions for Teaching the Blind to Read eloquently record the impression that such performances left on those attending. For example: 


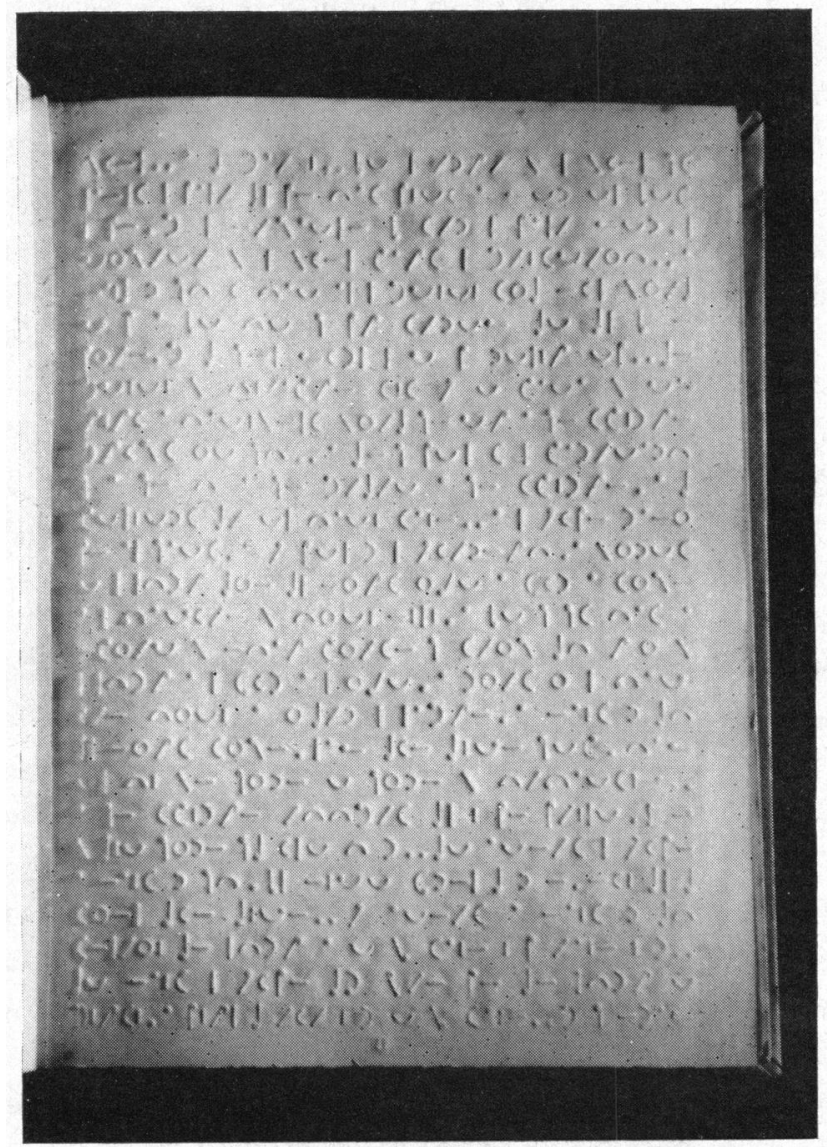

Fig. 1.-Lucas's embossed stenographic characters. A page of The Gospel According to Saint John, 1837. Original size, $10 \frac{3}{4} \times 8 \frac{3}{4}$ in.

On January 18, 1837, Mr. Lucas . . . delivered a free Lecture in our Guildhall [Bath], on teaching the blind to read with the most simple characters, and his Worshipful the Mayor presided on the occasion, when two blind pupils went through a regular examination, and read portions of the Scriptures, etc. so correctly and with such rapidity, that the attentive, numerous, and very respectable assembly were inspired with joy and wonder, so that the pupils were employed upwards of an hour after the close of the lecture.

In 1832 Lucas opened a free school for the blind at 76 Old Market Street, Bristol, in which he taught the blind pupils to read his "Embossed Short Hand" and "English Grammar". As a result of the success of his method sixteen prominent Bristol citizens met on February 12, 1836, in the Lecture Room of the Philosophical Institution in Park Street, Bristol, to form "The Bristol Society for embossing and circulating the authorised version of the Bible for the use of the blind", using Lucas's system. The Gospel According to Saint John was the first volume to be published, dated July, 1837 (Fig. 2). The stenographic characters were embossed on both sides of sheets of thick cartridge paper. 


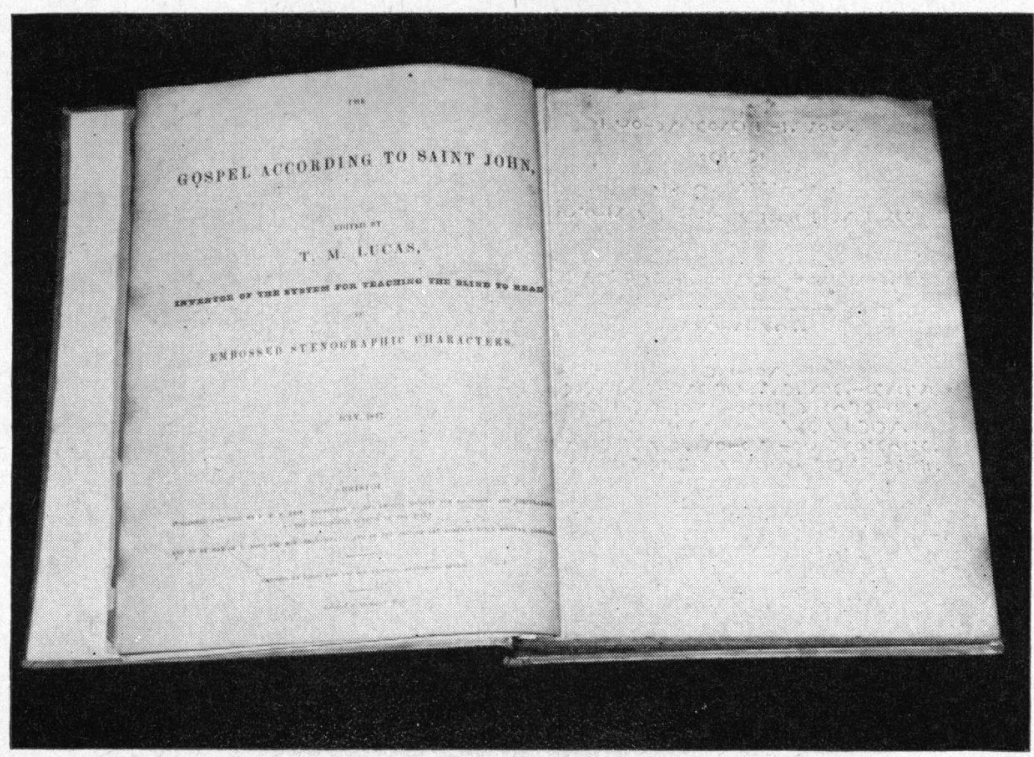

Fig. 2.-Title page of The Gospel According to Saint John, 1837.

In spite of this ready acceptance in his own city, Lucas encountered difficulties when trying to encourage others further afield to adopt his system. In particular, the Society of Arts for Scotland rejected it in favour of the embossed Roman characters developed by a Dr. Fry at the Glasgow Asylum. Lucas records "... the committee [of the Society of Arts for Scotland] met and decided in favour of Dr. Fry's Alphabet, without ever examining me or any person who had been taught by my system".

Such experiences no doubt stimulated him to move to London in the last year of his life in order to procure the more general use of his system. The success of his venture is evident from the first paragraph of the first Annual Report of "The London Society for Teaching the Blind to Read", presented on April 19, 1839:

The London Society for Teaching the Blind to Read was instituted in January 1838, and arose out of the circumstance of the late Mr. Lucas, of Bristol, coming to London, attended by some of his blind pupils. The extraordinary facility with which these pupils read, made so deep an impression on the minds of several individuals, at a special Meeting held at the Local School-room, Baldwin's Gardens, on January 12th, that it was considered desirable to form a Society for Teaching the Blind to Read, on the system recommended by $\mathrm{Mr}$. Lucas.

This society, which is now known as the Royal London Society for the Blind, has continued to provide education for blind persons ever since its formation was first inspired by Lucas.

Lucas died on May 18, 1838, but his system of characters, modified only by a reduction in the number of the contractions used, continued to be taught by the London Society for Teaching the Blind to Read until 1861. In that year it was superseded by the now universal Braille notation. During the intervening period 
Lucas's system was developed for foreign languages and music, and both scriptures and secular works in Lucas type were sent all over the country, as well as to India, China, and the Colonies.

Lucas nicely summarized the advantage of his system when he wrote "... the substitution of the Stenographic to the uncontracted Roman text, at once converts laborious spelling into facile reading". His revolutionary idea gave a new dimension to the education of blind persons. Though his characters were used for only thirty years, the spirit engendered by his invention resulted in changes which have persisted till the present day.

\section{REFERENCES}

LuCAS, T. M. (1837). "Instructions for Teaching the Blind to Read". Bristol, F. W. B. Reid. (1837). "The Gospel According to Saint John (Embossed Type)". Bristol, F. W. B. Reid.

Unsigned article (1957/58). R.L.S.B. Review (The Journal of the Royal London Society for the Blind), pp. 4, 5. 